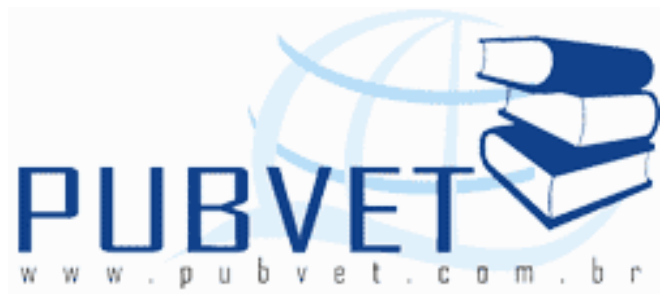

PUBVET, Publicações em Medicina Veterinária e Zootecnia.

\title{
Peritonite infecciosa felina - relato de caso
}

Humberto Eustáquio Coelho ${ }^{1}$, Tatiane Furtado de Carvalho², Hélio Alberto ${ }^{3}$, Juliana Marques Fernandes ${ }^{4}$, Karina Barbosa de Souza ${ }^{4}$, Flavia Maria Esteves Machado $^{5}$, Claudio Henrique Gonçalves Barbosa ${ }^{2}$

${ }^{1}$ Médico Veterinário, Mestre, Doutor, Professor de Patologia geral, Patologia Especial e Ornitopatologia da Universidade de Uberaba (UNIUBE). Av. do Tutuna, 720, Bairro Tutunas. CEP: 38061-500. Uberaba-MG.

${ }^{2}$ Médico(a) Veterinário(a), residente de Patologia Animal do Hospital Veterinário de Uberaba (HVU) - Uberaba/MG. Avenida do Tutuna, no 385, Bairro Tutunas. CEP: 38061-500.

${ }^{3}$ Técnico do Laboratório de Anatomia Patológica do Hospital Veterinário de Uberaba (HVU) - Uberaba/MG.

${ }^{4}$ Graduanda em medicina veterinária pela Universidade de Uberaba.

${ }^{5}$ Médica Veterinário, Mestre, Doutora, Professora de Zoonose e Epidemiologia na Universidade de Uberaba (UNIUBE).

\section{Resumo}

A peritonite infecciosa felina (PIF) é uma doença fatal dos felídeos, causada por um coronavírus, caracterizada por vasculite e serosite fibrinosa. Este trabalho tem como objetivo relatar a ocorrência de Peritonite Infecciosa Felina em um gato sem raça definida, macho, pesando dois quilogramas, adulto, não sendo possível se determinar a idade exata. Na necropsia os achados 
COELHO, H.E. et al. Peritonite infecciosa felina, relato de caso. PUBVET, Londrina, V. 6, N. 22, Ed. 209, Art. 1393, 2012.

macroscópicos se caracterizaram por edema ocular, peritonite serofibrinosa aguda, perihepatite fibrinosa, pleurite fibrinosa aguda, presença de líquido citrino na cavidade abdominal, rim com lesões piogranulomatosas e lesões granulomatosas recobrindo o omento, mesentério e a serosa intestinal. 0 diagnóstico da PIF é feito através da avaliação do histórico, achados clínicos, resultados laboratoriais e exclusão de doenças semelhantes. O diagnóstico definitivo é feito através da necropsia e histopatologia.

Palavras-chave: Felis catus, vasculite, coronavírus, patologia.

\title{
Infeccious peritonitis in cats - case reports
}

\begin{abstract}
Infectious peritonitis feline is a fatal disease of wild and domestic felines, caused by is a coronavirus, characterized by fibrinous serositis and perivasculitis. This study aimed to report a case of Infectious peritonitis feline in a cat cross breed, male, weighing 4,4 pounds, adult, it is not possible to determine their exact age. At necropsy an macroscopic findings characterized for ocular edema, acute peritonitis serofibrinosa, liquid in abdominal cavity and kidney lesions pyogranulomatous covering the omentum, mesentery and intestinal serosa. The diagnosis of FIP is realized by evaluating the historical, clinical findings, laboratory results and exclusion of similar diseases. The definitive diagnosis is made through the necropsy and histopathology.
\end{abstract}

Keywords: Felis catus, vasculitis, coronavirus, pathology.

\section{INTRODUÇÃO}

A peritonite infecciosa felina (PIF) é uma doença infecto-contagiosa, imunomediada fatal de incidência mundial, que acomete felídeos domésticos e selvagens (HOSKINS; LOAR, 1993; MCREYNOLDS; MACY, 1997).

São fatores predisponentes o tempo de exposição ao vírus, susceptibilidade genética, capacidade imune, estresse, infecções intercorrentes com os vírus da leucemia felina (FeLV) e da imunodeficiência felina (FIV) 
COELHO, H.E. et al. Peritonite infecciosa felina, relato de caso. PUBVET, Londrina, V. 6, N. 22, Ed. 209, Art. 1393, 2012.

(HOSKINS; LOAR, 1993; HERREWEGH et al., 1995; WOLF, 1996) e idade, sendo que Hoskins (1993) acredita que gatos entre três meses e cinco anos são mais acometidos, enquanto que outros autores afirmam que há maior prevalência entre dois meses e três anos e acima de dez anos (McREYNOLDS; MACY, 1997). Animais que vivem em locais com alta densidade populacional apresentam maior susceptibilidade (FOLEY et al., 1997; ADDIE; JARRETT, 1998), sendo a PIF caracterizada por baixa morbidade e alta taxa de mortalidade (100\%) (BARKER, 1993).

O agente etiológico da PIF é um coronavírus envelopado com RNA fita simples denominado Vírus da Peritonite Infecciosa Felina (FIPV) (HERREWEGH et al., 1995), oriundo de mutações no genoma durante a replicação intestinal do coronavírus entérico felino (FeCoV) em gatos com infecção ativa, sendo indistinguível deste último em relação às propriedades físicas e antigênicas (ADDIE; JARRETT, 1998). Enquanto que o FeCoV apresenta tropismo pelo epitélio apical maduro dos vilos intestinais, replicando-se nos enterócitos causando diarréia ou infecção assintomática, limitada ao sistema digestório (HERREWEGH et al., 1995; KIPAR, et al., 2005), o FIPV se replica em macrófagos, e dissemina-se para os órgãos pelo sangue, ocasionando infecção sistêmica e PIF (KIPAR, et al., 2005).

O FIPV replica-se no epitélio intestinal, nas tonsilas e nos linfonodos regionais. A viremia que ocorre após a replicação primária resulta em infecção de macrófagos, provocando uma viremia secundária, associada à disseminação dos macrófagos (BARKER, 1993). A viremia persistente que se segue à infecção e o envolvimento do sistema imune resulta numa reação de hipersensibilidade do tipo III, com a deposição de imunocomplexos em diversos órgãos e sistemas e/ou do tipo IV, com a formação de granulomas (FOLEY et al., 1998).

O vírus é eliminado pelas secreções (orais, respiratórias) e excreções (fezes e possivelmente urina) de gatos infectados, a transmissão ocorre por via fecal-oral, oral-oral e oral-nasal (WOLF, 1996), ou seja, por inalação ou 
COELHO, H.E. et al. Peritonite infecciosa felina, relato de caso. PUBVET, Londrina, V. 6, N. 22, Ed. 209, Art. 1393, 2012.

ingestão sob condições de contato íntimo, sendo provável que ocorra transmissão transplacentária (AUGUST, 1992; BARKER, 1993).

A PIF é classificada em duas formas: uma efusiva ou "úmida", caracterizada por vasculite e poliserosite - que ocasiona efusões pleural e peritoneal, e uma forma não-efusiva ou "seca", caracterizada por lesões granulomatosas em órgãos parenquimatosos (KIPAR et al, 2005), sistema nervoso central, olhos e intestinos. Alguns autores consideram uma terceira forma, sendo esta mista, que resultaria da combinação das formas supracitadas (AUGUST, 1992). Histologicamente, a PIF consiste de uma inflamação predominantemente piogranulomatosa localizada ao redor de vasos, principalmente de vênulas (BARKER, 1993).

O desenvolvimento da doença depende da resposta imunológica que o animal desenvolve após uma primeira infecção (BARKER, 1993; WOLF, 1996). A PIF não efusiva resulta de uma imunidade celular incapaz de barrar o vírus, enquanto que gatos que produzem resposta imune humoral, mas não desenvolvem imunidade celular desenvolvem a PIF efusiva (BRAUND, 1994; WOLF, 1996). Nesse caso, os macrófagos com vírus se acumulam ao redor de vasos e no interstício dos tecidos. As lesões vasculares causam, então, a efusão dos fluidos ricos em proteína, característicos da PIF efusiva (BARKER, 1993).

Diversas são as manifestações clínicas, incluindo alterações sistêmicas gerais como desidratação, febre, anorexia, apatia, perda de peso, vômito, diarreia, anemia (BIRCHARD; SHERDING, 2008), icterícia; alterações oftálmicas como uveíte, descolamento de retina, corioretinite; (MCREYNOLDS; MACY, 1997; ADDIE; JARRETT, 1998); distúrbios neurológicos como paresia dos membros pélvicos, ataxia, nistagmo, anisocoria, mudanças no comportamento, apreensão, tetraparesia e tremores (BRAUND, 1994); hepatopatias e nefropatias (BIRCHARD; SHERDING, 2008), podendo ocorrer também pirexia e dispneia e abdômen distendido (forma efusiva) (BARKER, 1993). 
COELHO, H.E. et al. Peritonite infecciosa felina, relato de caso. PUBVET, Londrina, V. 6, N. 22, Ed. 209, Art. 1393, 2012.

O diagnóstico da PIF é possível com base no histórico, sinais clínicos, resultados laboratoriais, títulos de anticorpos anticoronavírus, e do diagnóstico diferencial (HOSKINS; LOAR, 1993). A avaliação da efusão tem grande importância no diagnóstico presuntivo (ADDIE; JARRETT, 1998), no entanto, o diagnóstico definitivo é feito através da necropsia e histopatologia (BARKER, 1993; HERREWEGH et al., 1995; FOLEY et al., 1998).

Estudos têm sido realizados para se conseguir uma forma de diagnóstico sensível e específico ante mortem para PIF. Em um estudo preliminar, Monteleone et al. (2005) padronizaram um método de diagnóstico utilizando a reação em cadeia pela polimerase (PCR) a partir do RNA extraído de amostras de soro sanguíneo e efusões. Mas segundo Herrewegh et al. (1995), o PCR ainda não distingue o VPIF do FeCoV. . Hora e Brandão (2010) realizaram a identificação do RNAm dos FCoVs em amostras de efusões cavitárias de felinos demonstrando uma boa ferramenta diagnóstica de PIF ante mortem.

As alterações hematológicas incluem anemia, neutrofilia com aumento de neutrófilos segmentados, linfopenia e eosinopenia podendo-se observar hipoproteinemia, hipergamaglobulinemia e hipoalbuminemia (HERREWEGH et al., 1995).

Inexiste diagnóstico ante-mortem definitivo, tratamento efetivo ou vacina confiável, sendo a eutanásia indicada em gatos gravemente acometidos. A profilaxia é o controle mais eficaz, consistindo em controle ambiental e higiene (BIRCHARD; SHERDING, 2008).

O objetivo deste trabalho foi relatar a ocorrência de Peritonite Infeccciosa Felina em um gato sem raça definida.

\section{RELATO DE CASO}

Um gato, macho, sem raça definida, pesando dois quilos, adulto, não sendo possível se determinar a idade exata, foi encaminhado ao Hospital Veterinário de Uberaba (HVU), com a queixa de anúria e ausência de evacuação. O animal recebia alimentação caseira, apresentava vacinação e 
COELHO, H.E. et al. Peritonite infecciosa felina, relato de caso. PUBVET, Londrina, V. 6, N. 22, Ed. 209, Art. 1393, 2012.

vermifugação atrasadas. A proprietária havia pegado o animal na rua há um mês, este apresentava sinais de mordida por outros animais.

Ao exame clínico geral, as mucosas apresentavam hipocoradas, temperatura normal, desidratação moderada, tempo de preenchimento capilar de três segundos, frequência respiratória e cardíaca normais. Ao exame físico apresentava abdômen distendido.

Ao exame clínico especial do sistema digestivo, o animal apresentava vômito independente da ingestão de alimentos, as fezes se caracterizavam de forma diarreica e pastosa, não sendo possível delimitar as vísceras na palpação abdominal e apresentando som timpânico na percussão abdominal.

Foram solicitados exames bioquímicos e hematológicos. As bioquímicas solicitadas foram ureia, creatinina e fosfatase alcalina. A ureia apresentou $447,50 \mathrm{mg} / \mathrm{dL}(42,8-64,2 \mathrm{mg} / \mathrm{dL})$, a creatinina $5,9 \mathrm{mg} / \mathrm{dL}(0,8-1,8 \mathrm{mg} / \mathrm{dL})$, caracterizando uma grave azotemia. A fosfatase alcalina apresentou $27,5 \mathrm{U} / \mathrm{L}$, dentro dos valores de referências (25-93U/L).

No hemograma se observou apenas proteínas plasmáticas aumentadas. No leucograma observou uma leucocitose, caracterizada por uma neutrofilia com desvio a esquerda.

Devido ao comprometimento do estado clínico do paciente e do seu prognóstico bastante desfavorável, o animal veio a óbito.

Na necropsia realizada no Laboratório de Anatomia Patológica do HVU, o animal apresentava-se em péssimo estado geral (Figura 1), os achados macroscópicos se caracterizaram por edema ocular (Figura 1), peritonite serofibrinosa aguda, perihepatite fibrinosa, pleurite fibrinosa aguda, presença de líquido citrino na cavidade abdominal, rim com lesões piogranulomatosas (Figura 2) e lesões granulomatosas recobrindo o omento, mesentério e a serosa intestinal (Figura 2). 


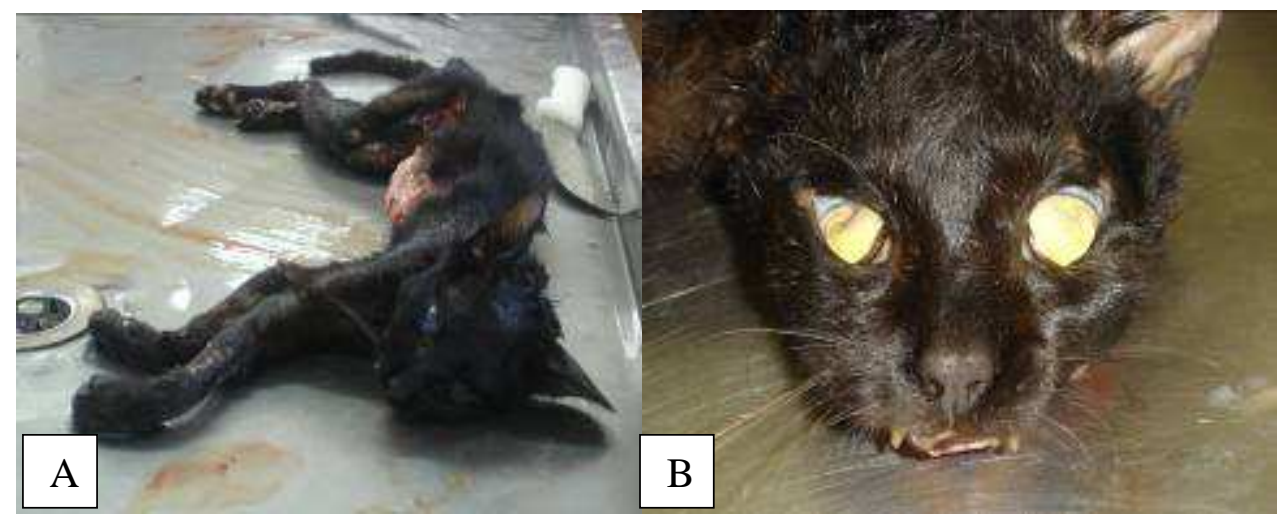

Figura 1- Gato apresentando estado geral ruim e edema de córnea.

A: Aspecto de "olho azul". B: Edema de córnea.

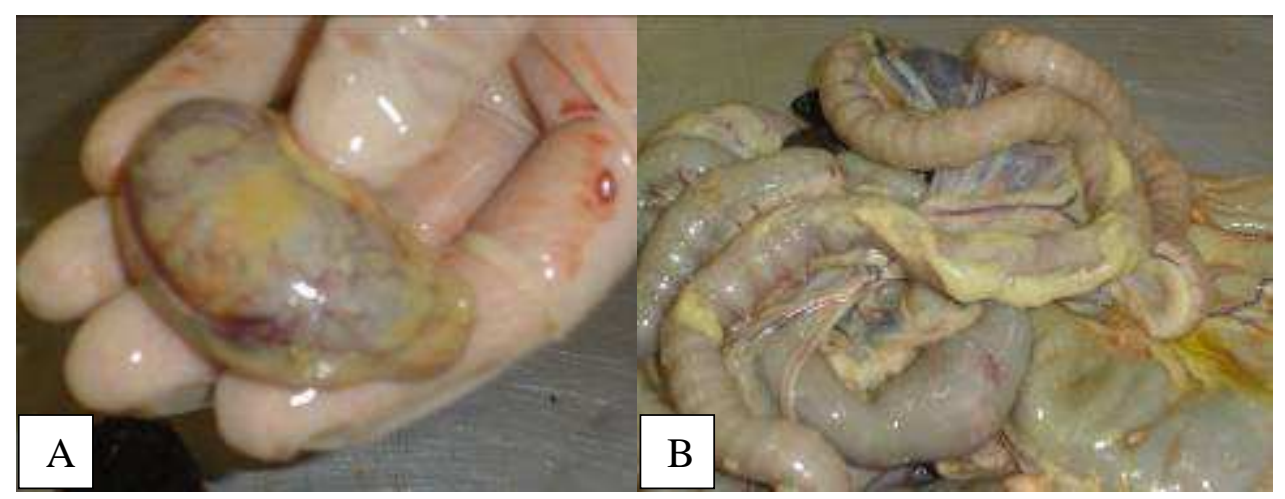

Figura 2 - Lesões macroscópicas à necropsia.

A: Rim apresentando lesões piogranulomatosas. B: Lesões fibrinosas recobrindo a serosa intestinal

\section{DISCUSSÃO}

O animal do presente relato é adulto, não sendo possível determinar sua idade exata. Segundo a anamnese, o paciente possuía acesso à rua, tendo contato com gatos errantes, sendo possível que esses animais tenham sido a fonte da infecção, devido à alta densidade de animais nas ruas levando à alta exposição viral e ao estresse (FOLEY et al., 1997; ADDIE; JARRETT, 1998) desencadeado por brigas que podem ser relacionadas as lesões de mordedura no animal, podendo este ter sido recolhido das ruas no período de incubação da doença que segundo Birchard e Sherding (2008), varia de várias semanas a 
COELHO, H.E. et al. Peritonite infecciosa felina, relato de caso. PUBVET, Londrina, V. 6, N. 22, Ed. 209, Art. 1393, 2012.

anos. Existe também a possibilidade de que a proprietária tenha recolhido o animal das ruas infectado com FeCoV e o estresse pela mudança de ambiente tenha favorecido sua replicação intestinal e sua mutação, capacitando-o a causar a PIF (BIRCHARD; SHERDING, 2008).

A evolução dos sinais clínicos até a morte do gato deste estudo foi de vinte dias. Na maioria dos relatos, a doença evolui para a morte em uma a doze semanas, com prevalência de óbito em dois meses após o início dos sinais clínicos (McREYNOLDS; MACY, 1997).

Apesar de inespecíficos, o estado geral do animal em conjunto com os sinais clínicos do trato digestório e urinário foram compatíveis com Peritonite Infecciosa Felina (PIF). Essas alterações são descritas na literatura em associação à forma efusiva (HOSKINS; LOAR, 1993; MCREYNOLDS; MACY, 1997; ADDIE; JARRETT, 1998). Para auxiliar o diagnóstico foram solicitados exames complementares (hemograma e bioquímica sanguínea). O resultado do hemograma foi parcialmente compatível, pois não foi constatado anemia, linfopenia ou eosinopenia como citado por Herrewegh (1995), embora apresentasse neutrofilia com desvio à esquerda, indicando que a medula óssea do paciente reagiu à infecção. Segundo Barker (1993) e Wolf (1996) uma imunidade celular fraca determina a forma efusiva da PIF.

O animal apresentou concentração de proteínas plasmáticas séricas aumentada, podendo corresponder à desidratação ou a uma hipoalbuminemia com hipergamaglobulinemia comum em quadros de PIF (relação $A / G<0,4$ forte preditiva de PIF) (HERREWEGH et al., 1995; FOLEY et al., 1997). A azotemia foi causada pela insuficiência renal provocada pela nefrite piogranulomatosa (BICHARD; SHERDING, 2008). Um exame do líquido peritonial seria interessante para ajudar a definir o diagnóstico e o prognóstico (ADDIE; JARRETT, 1998).

Os achados necroscópicos condizem com os mencionados na literatura para PIF como consequência da vasculite provocada pela deposição de imunocomplexos no endotélio vascular levando à efusão peritonial provocada pelo aumento de permeabilidade vascular e superfície serosa com aspecto granular 
COELHO, H.E. et al. Peritonite infecciosa felina, relato de caso. PUBVET, Londrina, V. 6, N. 22, Ed. 209, Art. 1393, 2012.

por estar recoberta com exsudato serofibrinoso característico da forma efusiva (BARKER, 1993; MCREYNOLDS; MACY, 1997; ADDIE; JARRETT, 1998), além da formação de granulomas, causados pelas reações de hipersensibilidade do tipo III e tipo IV, respectivamente (FOLEY et al., 1998). As lesões piogranulomatosas são pequenos granulomas, que consistem em macrófagos e neutrófilos, células atingidas pelo FPIV. O comprometimento oftálmico caracterizado por edema de córnea bilateral não condiz com a literatura, que afirma que lesões oculares só ocorrem na forma não efusiva da doença sendo a uveíte e corioretinite os achados mais comuns (McREYNOLDS; MACY, 1997; ADDIE; JARRETT, 1998). Apesar de não ter sido realizado exame histopatológico, as lesões piogralunomatosas associadas à efusão peritonial permitiram o diagnóstico post mortem de PIF.

\section{CONCLUSÃO}

Devido à dificuldade de se estabelecer um diagnóstico ante mortem, inexistência de tratamento efetivo e a alta taxa de mortalidade, o presente relato vem alertar aos criadores e veterinários sobre a doença e a importância de sua profilaxia, que é simples e eficaz.

\section{REFERÊNCIAS}

ADDIE, D. D.; JARRETT, O. Feline coronavirus infection. In: GREENE, C. E. Infectious diseases of the dog and cat. Athens, Georgia : Saunders, 1998. cap.11, p.58-69.

AUGUST J. R. Moléstias virais felinas. In: ETTINGER J. S. Tratado de medicina interna veterinária. 3. ed. São Paulo: Manole, 1992. v.1, p.328-356.

BARKER I. K. The peritoneum and retroperitoneum. In: JUBB K. V. F., KENNEDY P. C., PALMER N. Pathology of domestic animals. 4. ed. California: Academic Press, 1993. v.2, p.425-445.

BICHARD, S. J.; SHERDING, R. G. Manual Sauders: Clínica de pequenos animais. 3. ed. São Paulo: Rocca. 2008. p.135-146.

BRAUND, K.G. Neurological diseases. In: BRAUND, K.G. Clinical syndromes in veterinary neurology. St. Louis: Mosby, 1994. cap.3, p.81-333.

FOLEY, J. E.; POLAND, A.; CARLSON, J.; PEDERSEN, N. C. Risk factors for feline infectious peritonitis among cats in multiple-cat environments with endemic feline enteric coronavirus. Journal of American Veterinary Medical Association, v.210, n. 9, p.1313-1318, 1997. 
HERREWEGH, A. A. P. M., GROOT, R., CEPICA, A., EGBERINK, H F., HORZINEK, M. C., ROTTIER, P. J. M. Detection of feline Coronavirus RNA in feces, tissues, and body fluids of naturally infected cats by reverse transcriptase PCR. Journal of Clinical Microbiology, v.33, p.564-569, 1995.

HORA, A. S.; BRANDÃO, P. E. Detecção do RNA Mensageiro dos Coronavírus Felino em Amostras Post Mortem de Felinos com Manifestações Clínicas de Peritonite Infecciosa Felina. Anais da Semana Científica Benjamin Eurico Malucelli, v.4, 2010.

HOSKINS, J.D.; LOAR, A.S. Feline infectious diseases. Veterinary Clinics of North America, v.23, n.1, p.2-11, 1993.

KIPAR, A., MAY, H., MENGER, S., WEBER, M., LEUKERTAND, W.; REINACHER, M. Morphologic features and development of granulomatous vasculitis in feline infectious peritonitis. Veterinary Pathology, v.42, p.321-330, 2005.

McREYNOLDS, C.; MACY, D. Feline infectious peritonitis. Part I. Etiology and diagnosis. Compendium Continuing Education of the Practicing Veterinarian, v.19, n.9, p.10071012, 1997.

MONTELEONE, G. S.; BRANDÃO, P. E.; DEMÉTRIO, C.; GREGORI, F.; ROSA, C.; ROSALES, C. A. R.; SOARES, P.; SOARES, R. M.; VILLARREAL, L. Y. B.; RICHTZENHAIN, L. J.; JEREZ, J. A. Deteç̧ão do vírus da peritonite infecciosa felina (FIPV) por meio da PCR. ARS VETERINARIA, Jaboticabal, SP, v.21, n.1, p.030-033, 2005.

WOLF A. M. Peritonite infecciosa felina. Pet Vet, v.1, n.2, p.9-13, 1996. 